cient to produce transplantation immunity in homotransplantation. The causes of the weak reaction found in a few cases and the general antigenic activity of isolated tissue deoxyribonucleic acid are being further studied.

We wish to thank Dr. Kohoutová of the Biological Institute for supplying and testing the pneumococcal transformation factor.

\section{V̌̌RA HaŠKová}

Miroslava Hrubešová

Biological Institute of the

Czechoslovak Academy of Science,

Na cvičišti 2, Prague 6.

1 Billingham, R. E., Brent, L., and Medawar, P. B., Nature, 178, 514 (1956).

Zamenhof, St., Griboff, G., and Marullo, N., Biochim. Biophys. Acta, 13, 459 (1954).

EXPERIMENTS in this laboratory on the lines described above by Hašková and Hrubešová confirm their finding that preparations of deoxyribonucleic acid may provoke a foeble transplentation immunity that is detectable by homografts of skin. Splenic nuclear fragments from mice (usually of strain $A$ ) were washed six times in $0.15 M$ sodium chloride or in $0.15 M$ sodium chloride - $0.01 M$ sodium versenate at $p H \quad 7 \cdot 0$. Deoxyribonucleic acid was prepared from these nuclear fragments either by the sodium xylene sulphonate method (personally communicated by Dr. N. S. Simmons) or by dissolving them in $2 M$ sodium chloride, spinning at $25,000 \mathrm{~g}$ for $30-60 \mathrm{~min}$., and deproteinizing the supernatant by up to nine successive emulsifications with chloroform-amyl alcohol mixture'. The former preparation was completed by precipitation with $0.54 \mathrm{vol}$. isopropyl alcohol in the presence of $0.3 \mathrm{M}$ neutral sodium acetate, and the latter by precipitation with 0.2 vol. ethyl alcohol in the presence of $0.15 M$ sodium chloride-0.1 $M$ calcium chloride ${ }^{2}$. In either case the fibres of deoxyribonucleate were blotted free from excess of fluid, cut up into coarse fragments under a balanced salt solution, and allowed to swell into stiff transparent jellies. In this form they were injected into recipient mice (usually of strain $C B A$ ), each mouse receiving about $5 \mathrm{mgm}$. deoxyribonucleic acid. The survival scores $^{8,4}$ at six days of test skin homografts transplanted three to five days after the injection ranged from 25 per cent (indicating a definite state of sensitivity) to 100 per cent (the normal or 'control' response). Great pains were taken throughout the preparations to ensure that the deoxyribonucleic acid was in an undegraded state.

Although other possibilities have been considered (including a transformation of host cells into cells with some of the antigenic properties of the donor) there is reason for believing that the feeble sensitivity provoked by these preparations was due to an antigenic impurity, probably of a polysaccharide nature. Recent evidence ${ }^{5}$ suggests that the determinant groups of the antigens responsible for the homograft reaction (like those which are responsible for 'enhancement'6) may be mucoid substances: they are inactivated by exposure to low concentrations of the pariodate ion and by incubation with extracts of Trichomonas foetus known to contain enzymes which destroy blood-group substances in man?. (The Trichomonas preparations were very kindly supplied by Dr. W. M. Watkins.) This interpretation is not inconsistent with the fact that 'transplantation' antigens are present in washed nuclear fragments ${ }^{4}$ and follow the deoxyribonucleoprotein through at least the earlier stages of purification, for hexosamine is now known to be present as an impurity in even quite highly purified preparations of deoxyribonucleoprotein $^{8}$. The nucleoprotein may possibly act as an adjuvant ${ }^{8}$, if only by presenting the antigen in a physically suitable form, and the same may be true of the deoxyribonucleate when it is injected by the method described above.

Because of its relevance to a hypothesis of 'transformation', it may be added that the repeated injection into mice, from birth onwards, of high doses of undegraded homologous deoxyribonucleic acid failed in twenty-five trials to produce any sign of transplantation tolerance, that is, failed to prolong the life of skin homografts afterwards transplanted from mice of the same strain as those which provided the deoxyribonucleic acid.

Department of Zoology,

\section{P. B. Medawar}

University College, London, W.C.1.

1 Mirsky, A. E., and Pollister, A. W., J. Gen. Physiol, , 30, 117 (1946). 2 MeCarty, M., and Avery, O. T., J. Exp. Med., 88, 97 (1946).

${ }^{3}$ Billingham, R. E., Brent, L., and Medawar, P. B., Proc. Roy. Soc., B, 143, 58 . E., Br.

'Billingham, R. E., Brent, L., and Medawar, P. B., Nature, 178, 514 (1956).

${ }^{5}$ Billingham, R. E., Brent, L., and Medawar, P. B., Transplantation Bull. (in the press).

${ }^{6}$ Kandutsch, A. A., and Reinert-Wenck, U., J. Exp. Med., 105, 125 (1957).

Aminoff, D., and Morgan, W. T. J., Biochem. J., 48, 74 (1951). Watkins, w. M., ibid., '54, xxxiii (1953).

'Snell, G. D., Ann. Rev. Microbiol., 11, 439 (1957).

\section{Influence of a Crude Hypothalamic Extract on the Acid Phosphatase Activity of Rat Pituitaries}

IN rat pituitaries incubated in vitro with hypothalamic extracts the ascorbic acid content falls. Extracts of other parts of the brain are less successful ${ }^{1}$. This experiment was used to confirm in vitro the earlier findings in intact animals that hypothalamic extracts are able to stimulate the release of several trophic hormones from the distal lobe of the pituitary ${ }^{2}$. In the present study we tried to use acid phosphatase activity as an indicator.

Fresh rat pituitaries were incubated in the KrebsRinger-phosphate medium for one hour, adding either a suspension of temporal lobe of the brain (mean weight $104 \mathrm{mgm}$.) or of the hypothalamic region, including the median eminence of the tuber cinereum and the walls adjacent to the third ventricle (mean weight $86 \mathrm{mgm}$.). Each pituitary was exposed to the influence of $1 \mathrm{ml}$. of suspension for $60 \mathrm{~min}$. The surface of the pituitary was then dried, the gland homogenized and the activity of acid phosphatase estimated by the method of King and Armstrong (K.A.).

In the pituitaries of male rats the activity after incubation in the pure medium corresponded to $2 \cdot 04 \pm 0.168$ K.A. units $/ \mathrm{gm}$. The addition of temporal lobe suspension to the medium yielded values of $2.08 \pm 0.097 \mathrm{~K}$.A. units $/ \mathrm{gm}$. The mean figures, however, for incubation with hypothalamic extract were $2 \cdot 79 \pm 0.175$ K.A. units/gm., the difference being thus highly significant $(P=0.01)$. Acid phosphatase activity of the brain tissue itself has no influence on the results, since in the temporal lobe $1.21 \pm 0.05$ K.A. units/gm. was found, practically the same value being present in the hypothalamic region (namely, 1.19 \pm 0.099 ).

These preliminary results do not permit conclusions to be drawn. It remains to be seen whether the acid phosphatase activity in the pituitary, incubated in 